\title{
Avaliação dos parâmetros de processos de compostagem/ vermicompostagem para resíduos orgânicos com inserção de embalagens oxibiodegradáveis
}

Evaluation of the parameters of processes composting/vermicomposting for organic waste with inserttion of packaging oxybiodegradable

Evaluacion de los parâmetros de los procesos de compostaje/vermicompostaje de residuos orgánicos con inserción de embalajes oxybiodegradable

Stéphanie Fonseca Acadêmica Eng. Ambiental, Unicentro, Brasil. stephanie.fonseca93@hottmail.com

Maiza Karine Barcia Acadêmica Eng. Ambiental, Unicentro, Brasil. maizabarcia@outlook.com

Tatiane Bonametti Veiga Professora Doutora, Unicentro, Brasil. tati.veiga@yahoo.com.br 


\title{
Revista Científica ANAP Brasil
}

\author{
ISSN 1984-3240 - Volume 14, número 35, 2021
}

\section{RESUMO}

A destinação inadequada dos resíduos sólidos urbanos no Brasil ainda é uma atividade habitual, uma vez que, na maioria dos municípios, cerca de metade dos resíduos coletados é composto de matéria orgânica, sendo que a maior parte desses resíduos são destinados para aterros e "lixões", sem tratamento prévio. O presente estudo propôs a avaliação da compostabilidade de embalagens oxibiodegradáveis com restos de alimentos e podas de árvore. Para o desenvolvimento da pesquisa foram montadas duas composteiras domésticas, com as seguintes proporções: $70 \%$ de materiais secos, $25 \%$ de orgânicos e $5 \%$ de embalagens oxibiodegradáveis. O monitoramento foi realizado por um período de 100 dias, segundo os parâmetros: temperatura, $\mathrm{pH}$, umidade e matéria orgânica. Durante a compostagem e a vermicompostagem, as composteiras não alcançaram a fase termofílica, o pH, em ambas, foi neutralizado, a umidade, ao final do processo, permaneceu próximo de $55 \%$ nas duas composteiras, conforme é recomendado na literatura e a eficiência de remoção de matéria orgânica no final do experimento foi, aproximadamente, 50\% e 52\% para compostagem e vermicompostagem, respectivamente. As embalagens não apresentaram boa descaracterização, portanto tem-se a necessidade de maiores estudos relacionados à decomposição de embalagens oxibiodegradáveis por meio da compostagem e da vermicompostagem.

PALAVRAS-CHAVE: Gestão de resíduos. Resíduos orgânicos. Resíduos sólidos urbanos.

\section{RESUME}

The inadequate disposal of urban solid waste in Brazil is still a habitual activity, since, in most municipalities, about half of the collected waste is composed of organic matter, and most of this waste is sent to landfills and "dumps", without prior treatment. The present study proposed the evaluation of the compostability of oxybiodegradable packaging with food waste and tree prunings. For the development of the research two home compost bins were set up, with the following proportions: $70 \%$ dry materials, $25 \%$ organics and 5\% oxybiodegradable packaging. The monitoring was performed for a period of 100 days, according to the parameters: temperature, $\mathrm{pH}$, humidity and organic matter. During composting and vermicomposting, the composters did not reach the thermophilic phase, the $\mathrm{pH}$, in both, was neutralized, the humidity, at the end of the process, remained close to $55 \%$ in both composters, as recommended in the literature and the efficiency of removal of organic matter at the end of the experiment was approximately 50\% and 52\% for composting and vermicomposting, respectively. The packages did not show good decharacterization, thus there is a need for further studies related to the decomposition of oxybiodegradable packages through composting and vermicomposting.

KEY WORDS: Waste management. Organic waste. Urban solid waste.

\section{RESUMEN}

La destinación inadecuaddos de los residuos sólidos urbanos en Brasil sigue siendo uma actividad regular, una vez que, em la mayoría de los municipios, casi la mitad de los residuos recogido son compuesto de materia orgánica, la mayor parte de estes residuos son destinados para vertedero e "lixões", sin tratamiento previo. El presente estudio propues la evaluación de la compostabilidade de las embalajes oxybiodegradables com restos de comidas e podas de árboles. Para el desenvolvimiento de la invesigación fueron montadas dos compostadores domésticas, con las seguientes proporciones: $70 \%$ de materiales secos y $25 \%$ de orgánico y $5 \%$ de embalajes oxybiodegradables. El supervisionamento fue realizado por un período de 100 días, segun los parámetros: la temperatura, pH, humedad y materia orgánica. Durante la compostaje y la vermicompostaje, las compostadores não alcançaram la fase termofílica, el pH, en ambos, fue neutralizado, la humedad, em el final de lo proceso, se mantuvo próximo de $55 \%$ em las dos compostadores, segun la recomendación de la literatura y la eficiencia de la eliminación de materia orgánica en fin del experimento fue, acerca de, 50\% e 52\% para compostaje y vermicompostaje, respectivamente. Tanto los resíduos como las embalajes no presentaran buena descaracterización, por lo tanto tem la necesidade de mayores estudios em relación à decomposición de las embalajes oxybiodegradables mediante la compostaje y la vermicompostaje.

PALABRAS-CLAVE: Gestión de residuos. Residuos orgánicos. Residuos sólidos urbanos. 


\section{Revista Científica ANAP Brasil}

ISSN 1984-3240 - Volume 14, número 35, 2021

\section{INTRODUÇÃO}

A geração de resíduos sólidos urbanos (RSU) tem intensificado ao longo dos anos, em consequência dos processos de urbanização e industrialização. Quando dispostos no meio ambiente, os resíduos causam inúmeros impactos que afetam diretamente a sustentabilidade do planeta e trazem consequências ao meio ambiente e a saúde pública.

A destinação inadequada dos RSU no Brasil ainda é uma atividade habitual. De acordo com a Associação Brasileira de Empresas de Limpeza Pública e Resíduos Especiais (ABRELPE), em seu "Panorama dos Resíduos Sólidos no Brasil", referente ao ano de 2018, a geração de resíduos atingiu um total de 79 milhões de toneladas, do qual 40,5\% dos resíduos coletados foram destinados de forma incorreta (ABRELPE, 2019). No país mais de $50 \%$ do total dos resíduos coletados é composto de matéria orgânica, sendo que grande parte deste resíduo é destinado para os aterros e "lixões", e, causam problemas ambientais e socioeconômicos.

No Brasil, a Política Nacional de Resíduos Sólidos (PNRS), foi instituída por meio da Lei Federal no 12.305, regulamentada pelo Decreto no 7.404, na qual apresenta princípios, objetivos e diretrizes para a gestão integrada e o gerenciamento ambientalmente correto dos resíduos sólidos (BRASIL, 2010a; 2010b).

A PNRS determina a compostagem como uma forma de destinação final ambientalmente correta para os resíduos orgânicos (BRASIL, 2010a). A compostagem pode ser definida como a degradação da matéria orgânica através de um processo monitorado de decomposição microbiana de oxidação e oxigenação, tendo como produto um composto orgânico rico em nutrientes (KIEHL, 1998). Segundo Dal Bosco et al. (2017), o êxito no processo de compostagem depende de condições propícias de temperatura, aeração, umidade, relação carbono/nitrogênio, $\mathrm{pH}$ e granulometria do material utilizado, como também sua interação com os microrganismos. Do mesmo modo, a vermicompostagem é caracterizada pela estabilização da matéria orgânica por meio de um processo de bioxidação que envolve a ação conjunta de minhocas e microrganismos (AQUINO; ALMEIDA; SILVA, 1992). A compostagem e a vermicompostagem são processos eficazes que utilizam métodos simples, de baixo custo e fácil monitoramento, podendo ser empregadas em ambientes domésticos ou comerciais.

As atividades humanas geram grandes quantidades de resíduos, os quais, causam sérios problemas de poluição. Contudo, quando manuseados adequadamente, podem suprir, com êxito esses problemas. Um dos produtos mais usados pela indústria para produção de bens de consumo é o polímero, utilizado para a confecção de muitos objetos, como roupas, embalagem de alimentos, produção de tintas, eletroeletrônicos e sacolas plásticas, tornando-se indispensável para o ser humano (DE PAOLI, 2008).

No entanto, o elevado uso de sacolas plásticas causa sérios problemas para a sociedade moderna, principalmente, quando descartados incorretamente, podem proporcionar muitos prejuízos ao meio ambiente (FOLLMANN et al., 2017).

Com o intuito de reduzir seus impactos ambientais, foi lançado no mercado sacolas que, de acordo com sua composição, deve-se degradar mais rapidamente, sendo denominadas de "sacolas oxibiodegradáveis". Tipicamente, esses plásticos são projetados para degradar em pequenos pedaços imperceptíveis no período de alguns meses ou anos, dependendo do método de descarte (PIVA; ORIKASSA, 2014). 
Dessa forma, tornam-se cada vez mais necessários estudos relacionados à decomposição de sacolas oxibiodegradáveis por meio da compostagem e da vermicompostagem.

\section{OBJETIVOS}

\subsection{Objetivo Geral}

Analisar e avaliar a eficiência da compostagem de resíduos sólidos orgânicos com a inserção embalagens de materiais oxibiodegradáveis.

\subsection{Objetivos específicos}

- Realizar análises físico-químicas para controle do processo de compostagem, segundo análise dos parâmetros: temperatura, $\mathrm{pH}$, umidade e matéria orgânica.

- Comparar os resultados da compostagem e vermicompostagem.

\section{METODOLOGIA}

O experimento foi desenvolvido na Universidade Estadual do Centro-Oeste (Unicentro), Campus Irati, na qual foram montadas duas composteiras domésticas. Em uma das composteiras foi realizada somente a compostagem, enquanto na outra houve a précompostagem, seguida da vermicompostagem.

A proporção foi definida com base nas recomendações de Kiehl (1985) sendo, 70\% de materiais secos (galhos de poda, folhas e cascas de árvores), 25\% de orgânicos, proveniente do restaurante universitário e $5 \%$ de materiais oxibiodegradáveis, oriundos de um estabelecimento da região.

A fim de comparar dois processos optou-se pela realização concomitante da vermicompostagem, processo que consiste na estabilização da matéria orgânica por meio do uso de minhocas e outros microrganismos (DOMÍNGUEZ; EDWARDS; SUBLER, 1997). De acordo com Dal Bosco et al. (2017), para que esse processo apresente um bom desempenho é essencial que sejam mantidas temperaturas mesofílicas (entre 30 a $45 \circ \mathrm{C}$ ), pois, valores extremos de temperaturas, tanto altos quanto baixos, impedem a sobrevivência das minhocas.

A vermicompostagem é um processo controlado que utiliza a ação conjunta de minhocas e microrganismos, sob condição aeróbica, com a finalidade de estabilizar a matéria orgânica, inviabilizando o grau poluente e contaminante dos resíduos (KIEHL, 1985)

Dessa maneira, o processo de vermicompostagem foi desenvolvido em duas etapas: pré-compostagem por 68 dias para que a temperatura ficasse ideal para a adição das minhocas; e depois a vermicompostagem com a introdução das minhocas e monitoramento por mais 32 dias.

Foram utilizadas minhocas da espécie Eisenia foetida, conhecida popularmente como minhocas vermelhas da Califórnia, pois elas convertem resíduos orgânicos pouco decompostos em material estabilizado, extraordinária proliferação e rápido crescimento (AQUINO; ALMEIDA; SILVA, 1992; DAL BOSCO et al., 2017). 


\section{Revista Científica ANAP Brasil}

ISSN 1984-3240 - Volume 14, número 35, 2021

\subsection{Monitoramento dos parâmetros físico-químicos}

As análises físico-químicas definidas como parâmetro de controle do processo de compostagem, pré-compostagem e vermicompostagem encontra-se no Quadro 1, segundo parâmetros descritos no Manual de Métodos de Análise de Solo no Brasil da Embrapa (TEIXEIRA et al., 2017).

Quadro 1 - Parâmetros monitorados nas composteiras e sua frequência

\begin{tabular}{|c|c|c|}
\hline Parâmetros & Unidade & Frequência \\
\hline Matéria Orgânica (MO) & $\%$ & Semanal \\
\hline $\mathrm{pH}$ & - & Diário \\
\hline Temperatura (T) & $\circ \mathrm{C}$ & Diário \\
\hline Umidade & $\%$ & Diário \\
\hline
\end{tabular}

Fonte: Adaptado de Teixeira et al., 2017.

Os parâmetros foram obtidos por meio de análises realizadas no Laboratório de Saneamento Ambiental e Qualidade da Água do Departamento de Engenharia Ambiental na Unicentro. 0 monitoramento foi realizado no período de 100 dias até o encerramento da etapa de maturação do composto.

\subsubsection{Temperatura}

A temperatura foi medida diariamente com o auxílio de um termômetro analógico. Após a leitura das temperaturas realizou-se a aeração das composteiras manualmente.

\subsection{2 $\mathrm{pH}$}

A determinação de $\mathrm{pH}$, assim como a temperatura, foi realizada diariamente por meio da medição em um potenciômetro com eletrodo imerso em uma mistura de $10 \mathrm{~mL}$ de amostra e $25 \mathrm{~mL}$ de água destilada (TEIXEIRA et al., 2017). As leituras foram realizadas com peagâmetro de bancada da marca Gehaka ${ }^{\circledR}$.

\subsubsection{Umidade}

O teor de umidade foi monitorado diariamente, para tanto, pesou-se $15 \mathrm{~g}$ de amostra que foi levada para secagem em estufa, a $105^{\circ} \mathrm{C}$ por 24 horas. Assim, a umidade foi calculada pela a diferença gravimétrica entre o peso da amostra antes e após a sua secagem na estufa, conforme a Equação 1 (TEIXEIRA et al., 2017).

$$
U(\%)=\frac{(M i-\operatorname{tar} a)-(M f-\operatorname{tar} a)}{(M i-\operatorname{tar} a)} * 100
$$

Onde:

$\mathrm{U}=$ Umidade (\%);

Tara $=$ Peso do cadinho (g);

$\mathrm{Mi}=$ Massa inicial (peso do cadinho + amostra) (g);

Mf = Massa final após 24 horas na estufa (peso do cadinho + amostra) (g). 


\section{Revista Científica ANAP Brasil}

ISSN 1984-3240 - Volume 14, número 35, 2021

\subsubsection{Matéria Orgânica}

O teor de matéria orgânica foi calculado semanalmente por meio da Equação 2, na qual utilizou-se a diferença gravimétrica entre o peso da amostra seca em estufa $\left(105^{\circ} \mathrm{C}\right.$ por 24 horas) e seu peso após incineração na mufla, a $550^{\circ} \mathrm{C}$ por 1 hora (TEIXEIRA et al., 2017).

$$
M O(\%)=\frac{(\mathrm{Mi}-\operatorname{tar} \mathrm{a})-(M f-\operatorname{tar} a)}{(M i-\operatorname{tar} a)} * 100
$$

Onde:

$\mathrm{MO}=$ Matéria orgânica (\%);

Tara = Peso do cadinho $(\mathrm{g})$;

$\mathrm{Mi}=$ Massa inicial após 24 horas na estufa (peso do cadinho + amostra) (g);

$\mathrm{Mf}=$ Massa final após 1 hora na mufla (peso do cadinho + amostra) (g).

\subsection{Análise estatística}

Para a análise dos dados encontrados em relação aos diferentes materiais utilizados para realizar a compostagem/vermicompostagem, foi verificada a eficiência de cada processo de compostagem e comparado por meio de análises estatísticas com a utilização do Teste t de Student, com nível de significância igual a 5\%.

\section{RESULTADOS E DISCUSSÃO}

\subsection{Monitoramento dos parâmetros físico-químicos}

O monitoramento das duas composteiras foi realizado simultaneamente, por aproximadamente 15 semanas, sendo que, uma delas foi monitorado o processo de précompostagem, na qual ocorreu em 68 dias e, posteriormente, a vermicompostagem em 32 dias.

\subsubsection{Temperatura}

Conforme demonstrado na Figura 1, as temperaturas das composteiras foram monitoradas diariamente ao longo de todo o experimento, ou seja, por um período correspondente a 100 dias. A temperatura é um dos principais fatores que controlam o processo da compostagem, a Figura 1 apresenta as variações de temperatura sofridas no decorrer do processo de compostagem e vermicompostagem. 
Figura 1 - Evolução da temperatura na compostagem e vermicompostagem

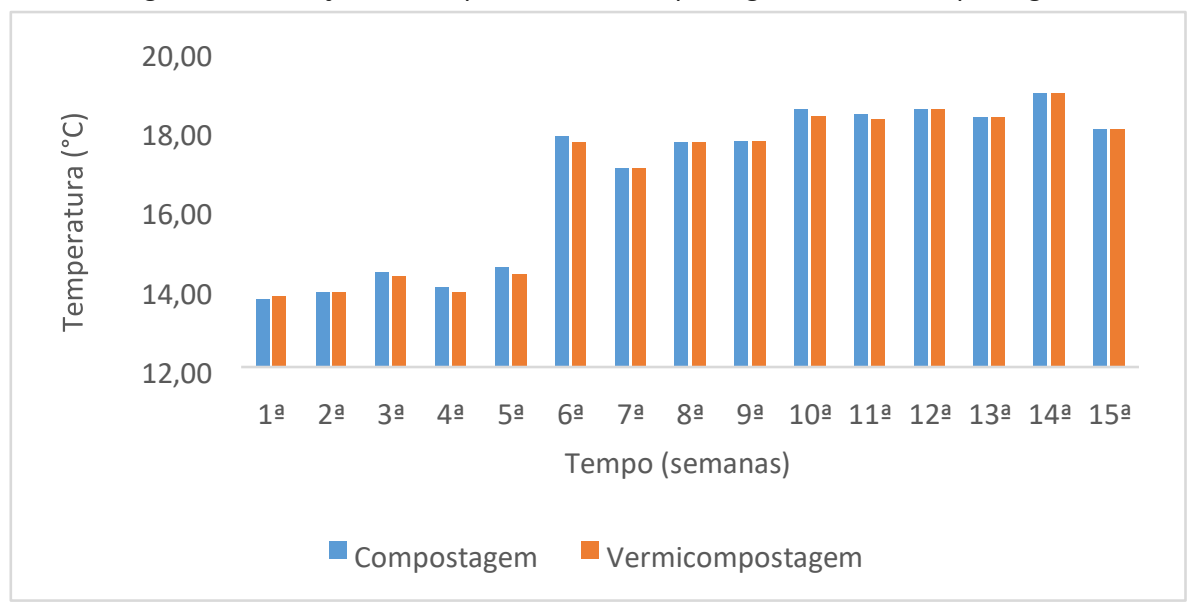

Fonte: Autoras, 2021.

A partir dos resultados obtidos, é possível observar que as temperaturas nas duas composteiras mantiveram-se baixas e não atingiram a faixa ideal que seria de 40 à $45^{\circ} \mathrm{C}$ (KIEHL, 1985). De acordo com Burle et al.(2018), nas primeiras semanas podem ocorrer dissipação de calor, não alcançando a fase termofílica por serem pilhas pequenas. O local da disposição também pode ter interferido para a obtenção de baixas temperaturas. De acordo com Lim, Lee e Wu (2016), as temperaturas baixas nas composteiras podem ocorrer devido a camada do material em decomposição conter dimensão insuficiente para reter calor e também em função da baixa temperatura ambiente ou das propriedades dos materiais utilizados para o composto.

\section{$4.1 .2 \mathrm{pH}$}

$\mathrm{O} \mathrm{pH}$, assim como a temperatura, foi monitorado durante todo o processo de compostagem e pré-compostagem/vermicompostagem, as medições deste parâmetro ocorreram diariamente. A Figura 2 apresenta os valores médios entre a compostagem e a précompostagem/vermicompostagem.

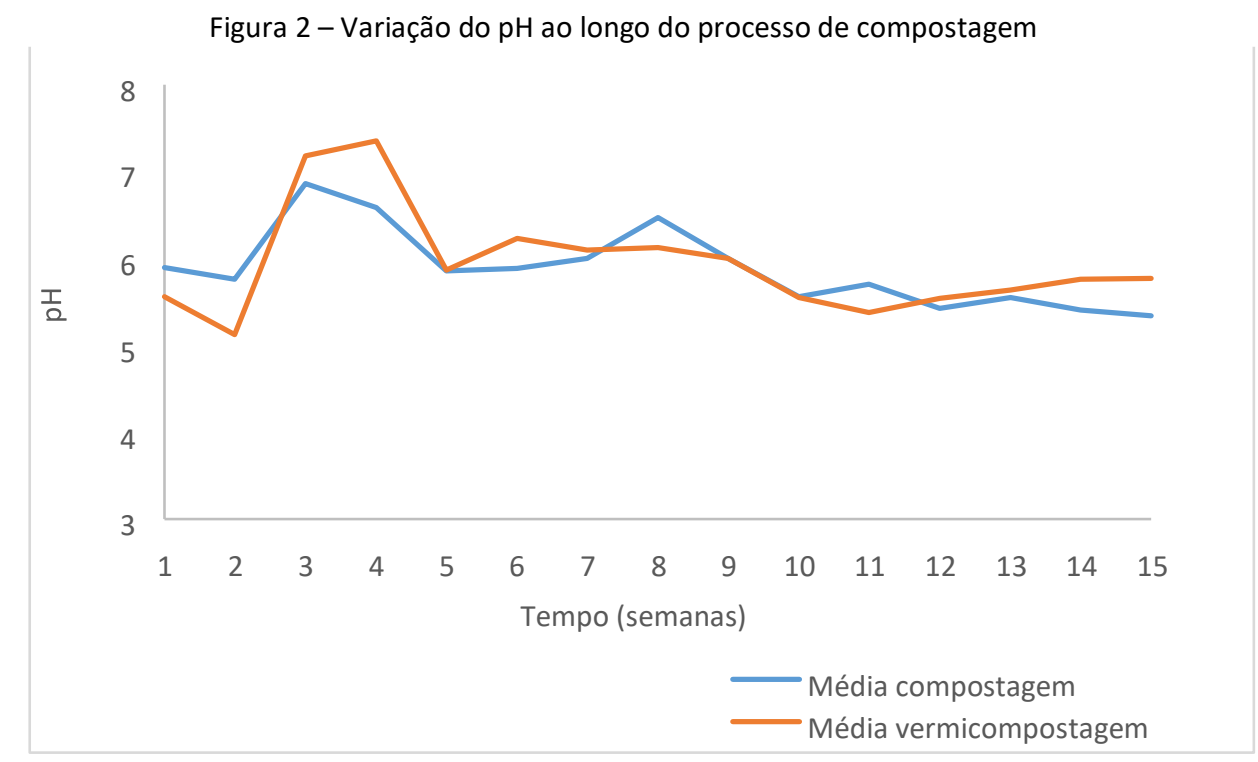




\section{Revista Científica ANAP Brasil}

ISSN 1984-3240 - Volume 14, número 35, 2021

Fonte: Autoras, 2021.Observa-se, para ambos os tratamentos, que houve a elevação do $\mathrm{pH}$ no decorrer da terceira e da quarta semana, tal fato ocorre devido à degradação dos compostos ácidos, liberação de amônia e hidrólise de proteínas (OLIVEIRA, 2013). Portanto, no final do experimento, ambos os compostos apresentaram pH próximo da neutralidade, pois a faixa de $\mathrm{pH}$ considerada ótima para o desenvolvimento dos microrganismos responsáveis pela compostagem devem permanecer entre 5,5 e 8,5, uma vez que a maioria das enzimas encontram-se ativas nesta faixa de pH (RODRIGUES et al., 2006).

\subsubsection{Umidade}

A umidade é indispensável para a atividade metabólica e fisiológica dos microrganismos, sendo considerada ideal para a compostagem (RODRIGUES et al., 2006). 0 controle da umidade foi realizado diariamente, a qual foi calculada pela diferença gravimétrica entre o peso da amostra antes e após a sua secagem na estufa, sendo apresentado na Figura 3.

Figura 3 - Teores de umidade nas composteiras

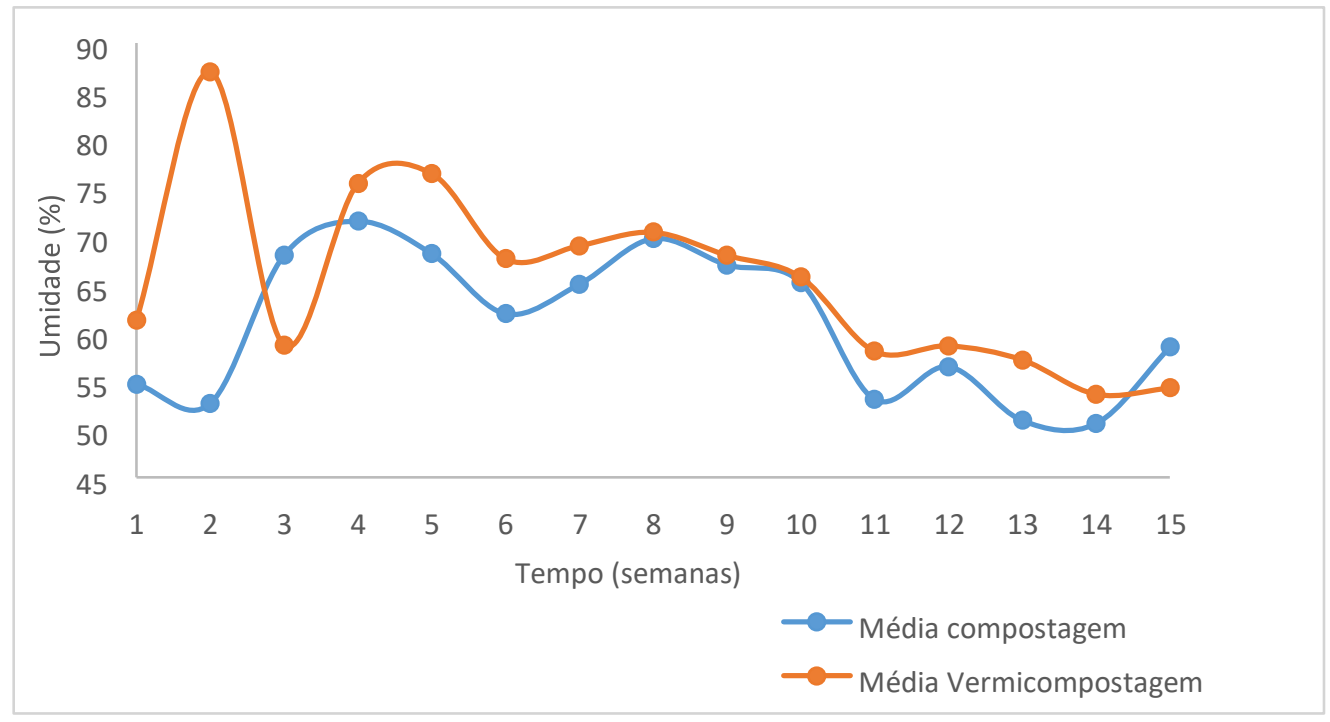

Fonte: Autoras, 2021.

Em relação aos teores de umidade, constatou-se que a umidade inicial nas composteiras variaram de $52 \%$ a $86 \%$, Na décima semana do experimento houve o acréscimo das minhocas da espécie Eisenia foetida, e pode-se perceber que o teor de umidade na vermicompostagem manteve-se acima dos teores de umidade da compostagem, visto que as minhocas necessitam de água para o transporte e solubilização de nutrientes, bem como, para realizar a maioria das reações químicas responsáveis pelo processo de degradação da matéria orgânica (OLIVEIRA, 2013). Ao final do processo da compostagem/vermicompostagem o teor de umidade, em ambas, permaneceu próximo de 55\%, conforme é recomendado na literatura (PEREIRA NETO, 2007).

\subsubsection{Matéria orgânica}

O teor de matéria orgânica apresenta os nutrientes e minerais presentes nos resíduos orgânicos (DORES-SILVA et al., 2013). A matéria orgânica foi calculada semanalmente, a partir 


\section{Revista Científica ANAP Brasil}

ISSN 1984-3240 - Volume 14, número 35, 2021

da diferença gravimétrica entre o peso da amostra seca em estufa e seu peso após incineração na mufla, obtendo os resultados conforme a Figura 4.

Figura 4 - Teores de matéria orgânica nos processos de compostagem

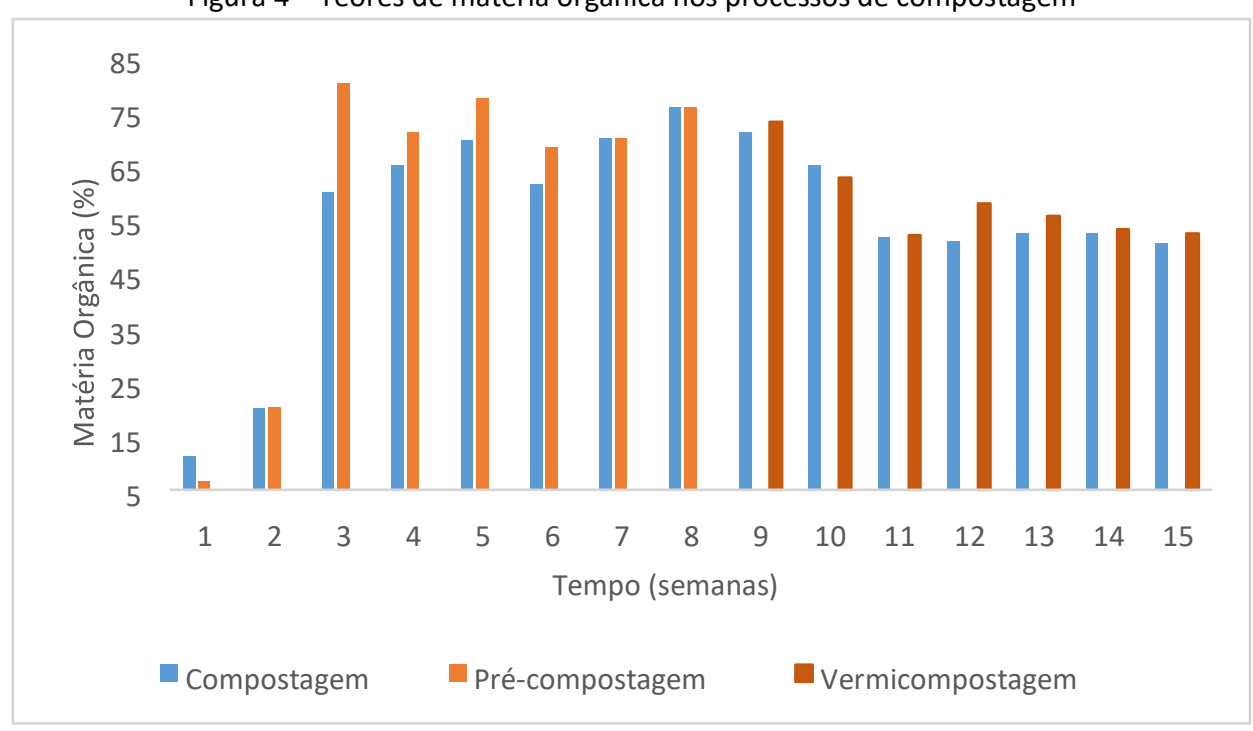

Fonte: Autoras, 2021.

Observa-se que a matéria orgânica diminuiu ao longo das semanas devido ao processo de mineralização, em que os microrganismos transformam a matéria orgânica em dióxido de carbono (KIEHL, 1998; DORES-SILVA et al., 2013). No final do experimento, a eficiência de remoção de matéria orgânica foi, aproximadamente, $50 \%$ e $52 \%$ para compostagem e vermicompostagem, respectivamente. Nas primeiras seis semanas a degradação da matéria orgânica para compostagem e pré-compostagem evoluíram de um modo distinto. Contudo, após a adição das minhocas, na décima semana, os sistemas de compostagem e vermicompostagem estabilizaram, apesar da vermicompostagem apresentar uma porcentagem maior quando comparada a compostagem.

\subsection{Análise estatística}

Com os dados obtidos, realizou-se a análise estatística pelo Teste t de Student, ao nível de $5 \%$ de significância, para comparar as médias entre o processo de compostagem e vermicompostagem, onde foram avaliados os parâmetros físicos químicos (Tabela 1).

Tabela 1 - Médias comparadas pelo Teste t de Student ao nível de 5\% de significância para as amostras obtidas na compostagem e na vermicompostagem

\begin{tabular}{ll}
\hline Parâmetros físico-químicos & P- valor \\
\hline Matéria Orgânica(MO) & $2,84^{-02}$ \\
\hline $\mathrm{pH}$ & $2,67^{-01}$ *ns \\
\hline Temperatura (T) & $1,77^{-02}$ \\
\hline Umidade (U) & $4,11^{-02}$
\end{tabular}

*ns - não significativo ao nível de 5\% de significância pelo teste $t$ de Student.Fonte: Autoras, 2021.

As análises realizadas indicaram uma significância $(P>0,05)$ entre os parâmetros físicoquímicos de matéria orgânica, temperatura e umidade, somente o pH não foi significativo ao nível de $5 \%$ pelo teste $t$ de Student. 


\section{Revista Científica ANAP Brasil}

ISSN 1984-3240 - Volume 14, número 35, 2021

\section{CONCLUSÃO}

O desenvolvimento do presente estudo possibilitou analisar a inserção de embalagens oxibiodegradáveis na compostagem e na vermicompostagem. A temperatura entre os processos não alcançou a fase termofílica, destacando que o processo de compostagem pode ter sofrido interferências das condições climáticas, devido à localização das composteiras. Já os resultados analisados quanto a umidade, matéria orgânica e pH encontraram-se semelhantes aos da literatura.

As embalagens plásticas oxibiodegradáveis não apresentaram alterações significativas na integridade física aparente, destacando-se a necessidade de um estudo contínuo e de maior duração, visto que algumas sacolas oxibiodegradavéis podem levar um tempo maior para se decompor.

Contudo, vale ressaltar que ambas as técnicas são aplicáveis em nível domiciliar e que essa prática, com o intuito de minimizar a quantidade de resíduos orgânicos encaminhados para os aterros sanitários é altamente viável devido a seu custo e acessibilidade.

\section{REFERÊNCIAS}

ABRELPE - ASSOCIAÇÃO BRASILEIRA DE LIMPEZA PÚBLICA E RESÍDUOS ESPECIAIS. Panorama dos Resíduos Sólidos no Brasil 2018/2019. São Paulo, p.68.

AQUINO, A.M., ALMEIDA, D.J., SILVA, V.F. Utilização de minhocas na estabilização de resíduos orgânicos: Vermicompostagem. Comunicado técnico - Embrapa Agrobiologia, (8), 1-6p., 1992.

BRASIL. Política Nacional dos Resíduos Sólidos. Lei no 12.305, de 02 de agosto de 2010. Institui a Política Nacional de Resíduos Sólidos. Diário Oficial da União. Brasília, DF, 03 ago. 2010a.

BRASIL. Decreto no 7.404, de 23 de dezembro de 2010. Regulamenta a Lei no 12.305, que institui a Política Nacional de Resíduos Sólidos. Diário Oficial da União. Brasília, DF, 23 dez. 2010b.

BURLE, E. C., NETO, E. C. A. de, SANTOS, W. L., FIGUEIREDO, R. T. Resíduos Orgânicos Com Óleos E Gorduras Residuais - Ogr. Ciências Exatas e Tecnológicas, 11-20p.,2018.

DAL BOSCO, T. C., GONÇALVES, F., ANDRADE, F. C., TAIATELE JUNIOR, I., SILVA, J. S., SBIZZARO, M. Contextualização teórica: compostagem e vermicompostagem. In: Dal Bosco, T. C. (Eds.) Compostagem e vermicompostagem de resíduos sólidos: resultados de pesquisas acadêmicas. Blucher, São Paulo, 19-43p., 2017.

DE PAOLI, M. A. Degradação e Estabilização de Polímeros. Chemkeys 2a versão on-line, 2008. Disponível em: <http://dx.doi.org/10.5902/2179460x24176>. Acesso em: 07 mar. 2020.

DOMÍNGUEZ, J.; EDWARDS, C.A.; SUBLER, S. A comparison of composting and vermicomposting. Biocycle, v.38, n.4, p.57-59, 1997.

DORES-SILVA, P.R., DIVA, M., OLÍMPIA, M., REZENDE, O. Processo de estabilização de resíduos orgânicos: vermicompostagem versus compostagem. Química Nova, 640-645p., 2013.

FOLLMANN, A. J. et. al. Degradação de sacolas plásticas básicas e oxibiodegradáveis. Ciência e Natura, 186-192 p., 2017.

KIEHL, E.J. Fertilizantes orgânicos. Piracicaba, Editora Agronômica Ceres Ltda, 492p. 1985.

KIEHL, E. J. Manual da Compostagem: Maturação e Qualidade do Composto, 4ạed, Piracicaba, 1998.

LIM, L. S.; LEE, L. H.; WU, T. Y. Sustainability of using composting and vermicomposting technologies for organic solid waste biotransformation: recent overview, greenhouse gases emissions and economic analysis. Journal of Cleaner Production, v. 111, p. 262-278, 2016. 


\section{Revista Científica ANAP Brasil}

ISSN 1984-3240 - Volume 14, número 35, 2021

OLIVEIRA, E.P. Compostagem da borra de óleos e gorduras residuais com bagaço de cana-de-açúcar e esterco bovino. Dissertação (Mestrado em Energia), Programa de pós graduação em Energia, Universidade Salvador, Salvador, 2013, p.128.

PEREIRA NETO, J.T. Manual de compostagem: processo de baixo custo. UFV. Viçosa, 81p. 2007.

PIVA, C. D.; ORIKASSA, T. N. F. Sacolas Plásticas: Sua utilização na visão de diferentes autores. Revista de Ciências Gerenciais. Campo Grande, 2014.

RODRIGUES, M.S.; SILVA, F.C.; BARREIRA, L.P.; KOVACS, A. Compostagem: reciclagem de resíduos sólidos orgânicos. In: Spadotto, C.A.; Ribeiro, W. Gestão de Resíduos na agricultura e agroindústria. FEPAF. Botucatu,2006. 63-94p.

TEIXEIRA, P. C.; DONAGEMMA, G. K.; FONTANA, A.; TEIXEIRA, W. G. Manual de métodos de análise de solo. 3. ed. Brasília, DF: Embrapa, 2017. 574 p. 